This result, however, had remained unchecked for three weeks.

\section{Recommendation}

Optimal, cost-effective use of in-clinic monitoring requires the establishment of dedicated lithium clinics where as many patients as possible attend. Our experience is that these clinics are best held at weekly intervals. The need for a blood check is evaluated on the clinical state of the patient as well as on the length of time since the last test. If the result is abnormal, corrective action may be taken straight away, and the results of the action checked the following week by which time the lithium level will have restabilised. The model, which we have now adopted permanently, provides complete flexibility and enables resistant patients to be more closely monitored on higher levels. Other patients may only need to be seen very infrequently unless a problem occurs unexpectedly.

\section{References}

Birch. N. J., Freeman, M.. Philups, J., et al (1992) The lithium ion selective electrode and its use in the lithium clinic: real time monitoring of plasma lithium. Lithium. 3. 133-137.
Cookson, J. (1997) Lithium: balancing risks and benefits. British Joumal of Psychiatry. 171, 120-124.

DE MONTIGNY, C. (1994) Lithium addition in treatmentresistant depression. International Clinical Psychopharmacology, 9 (suppl. 2), 31-35.

KING, J. R., PHILLIPS, J. D.. JUDGE, R., et al (1991) Instant lithium monitoring. Psychiatric Bulletin. 16. 138-139.

MONCRIEFF, J. (1997) Lithium: evidence reconsidered. British Journal of Psychiatry. 171. 113-119.

MYERS. D. H. \& HALLWORTH. M. J. (1996a) An investigation of high lithium concentrations. Psychiatric Bulletin, 20. 331-333.

- \& - (1996b) An investigation into lithium monitoring. Psychiatric Bulletin. 20, 333-334.

PEET, M. \& HARVEY, N. S. (1991) Lithium maintenance: a standard education programme for patients. British Journal of Psychiatry. 168, 197-200.

RYMAN, A. (1997) Lithium monitoring in hospital and general practice. Psychiatric Bulletin. 21, 570-572.

SCHOU, M. (1988) Effects of long-term lithium treatment on kidney function: an overview. Journal of Psychiatric Research, 22. 287-296.

- (1992) Lithium prophylaxis in perspective. Pharmacopsychiatry, 25, 7-9.

*J. R. King, Consultant Psychiatrist, Worcestershire Community Trust and Honorary Senior Lecturer, University of Birmingham. Hill Crest Clinic, Quinney's Lane, Redditch B98 7WG and N. J. Birch, Emeritus Professor of Biomedical Science, University of Wolverhampton

*Correspondence

\title{
Users' needs and satisfaction with a community-based mental health service
}

\author{
George Ralston, Sarah Beesley and John Bogue
}

There has been an increasing move to involve consumers in the assessment of health services. Needs assessment and consumer satisfaction of a recently setup community mental health feam is described.

Following the NHS and Community Care Act of 1990 the Greater Glasgow Community and
Mental Health Services NHS Trust have quickly progressed to a community model of care following years of institution-based services. The teams take direct referrals primarily from general practitioners, although referrals can be made by social services and voluntary agencies. One of the first community mental health teams (CMHTs) set up was the Goldenhill CMHT which 
is located in Clydebank, to the west of Glasgow. It services a general adult population (16-65) of approximately 50000 . This team opened in 1993 and its aim, as with all others, was to target the chronic persistent severe mentally ill population.

The views of consumers are seen as central to the monitoring of performance and the formulation of policy and have been put at the top of the health agenda (Department of Health and Social Services, 1983; Department of Health, 1989; Stallard et al, 1992).

Fitzpatrick (1991) suggests three reasons why consumers' views are essential to service providers. First, there is evidence that satisfaction is an important outcome measure in influencing treatment compliance and re-attendance for appropriate treatment. Second, satisfaction can provide a measure of assessing consultations and patterns of communication such as the provision of information and the involvement of the client in decisions about care and, third, patient feedback can be used to modify or propose alternative care practices.

Studies focusing on consumer views within community-based care settings have identified the readiness of users to express their views. However, users of CMHTs have not yet been asked for their satisfaction ratings nor has the literature revealed a survey of needs. This paper addresses these issues.

\section{The study}

The areas to be assessed were: the population attending the CMHT; accessibility; clients' needs; and clients' satisfaction with existing services.

All clients on the CMHT severely mentally ill register (those with long-term severe illness) in a single month were invited to participate in the study. We devised a questionnaire, appropriate to our study, as at that time no standard measure was appropriate. We consulted with staff and clients on what was required, used a standard format and piloted the questionnaire to confirm its suitability. Questionnaires were filled in by individual clients with the help of various staff members, if required.

The questionnaire covered the areas of: client characteristics (mental health problem, history, access to service, attendance details), clients' needs and satisfaction with the existing service. Clients' needs covered clinical problems such as: depression, anxiety, social skills, anger, addiction problems and general problems (help with isolation, independent living, knowledge about treatment, etc). Satisfaction covered two main areas, that of access/communication (involvement in treatment plan, ability to discuss problems, confidentiality, continuity with keyworker, etc) and clinical services (contact with the professional groups and specific services e.g. relaxation classes).

Interviews took place at the CMHT base or at home. Where necessary supplementary information was obtained from clients' keyworkers. Diagnoses were obtained from case-records and ICD-10 codes were assigned. All data were analysed using SPSS Release 6.0 (Norusis, 1993).

\section{Findings}

\section{Client epidemiology}

Of the 153 clients who participated, four did not complete the questionnaire and only demographic and diagnostic information was recorded for analysis. Therefore, 149 clients formed the main cohort, although in some cases clients failed to record responses so not all items total 149.

Sixty-four per cent of the study were female. the mean age of the cohort was 44 and no statistically significant association was found between age groups and gender. Eighty per cent had a primary diagnosis of either schizophrenia or mood disorder (schizophrenia, schizotypal and delusional disorders (F2) $=43.4 \%$; mood (affective) disorders (F3) $=36.7 \%$ ), with the majority of the mood disorder diagnoses being bipolar affective disorder or recurrent depressive disorder. Seventy per cent reported having had a mental health problem for a period in excess of four years and $67 \%$ had been receiving help for their mental health problem for two years or more. The mean number of hospital admissions was 3.5 (range 0-33) and the mean period of time elapsed since last admission was just over two years, with a median of 50 weeks. A statistically significant association was found between gender and diagnostic grouping $\left(\chi^{2}=15.9\right.$, d.f. 5 , $P=0.007$ ). Over four times as many women received an F30 mood disorder diagnosis compared to men in the sample.

\section{Access to the resource centre}

Fifty-nine per cent of clients used the CMHT base, with most attendees living within a 15 minute walk or bus ride from the centre. The remainder were seen at home or at a nearby health centre, with the vast majority $(80 \%)$ of clients being seen on time or early $(75 \%$ were seen at least fortnightly).

\section{Client needs}

Figure 1 illustrates the clinical and general needs rated most helpful by service users. Other clinical needs that were required, but not rated as highly, included help with sexual problems. eating problems and alcohol problems. Similarly, general needs mentioned included help with budgeting, coping with debt, practical help and assertiveness. 


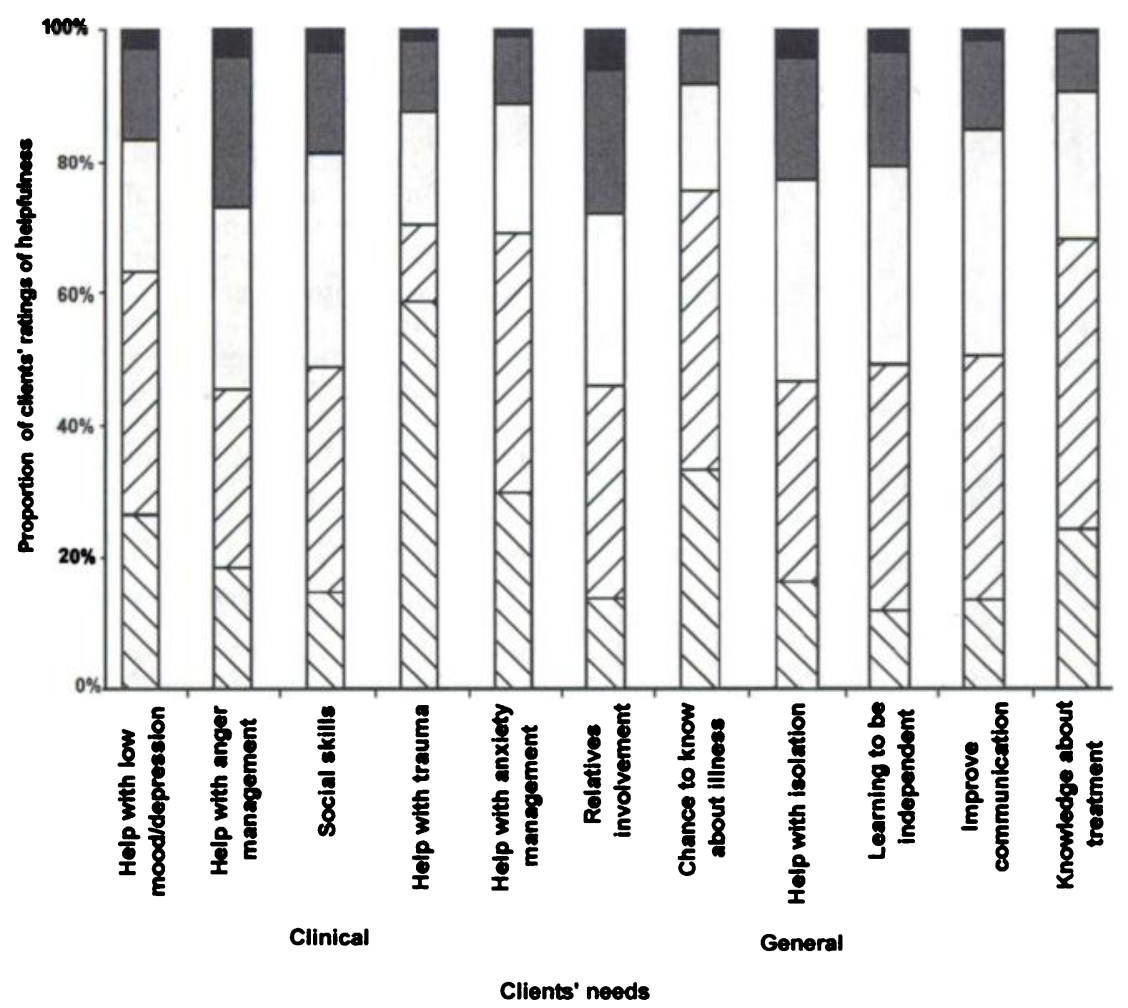

Fig. 1. Clients' clinical and general needs. $\mathbb{N}$, very helpful; $\mathbf{a}$, helpful; $\square$, neutral; $\mathbf{\square}$, unhelpful; very unhelpful.

Figure 2 shows that in general clients expressed consistently high levels of satisfaction with the service and aspects of service delivery. Other items from the survey not included in the figure, but rated highly, were contact with each professional grouping, relatives' service, financial advice service, confidentiality, staff openness, ease of access of staff and service being close to home.

\section{Comment}

It is rewarding to see that over $80 \%$ of the sample had a primary diagnosis of either F2 schizophrenia disorder or F3 mood disorder. This, coupled with the average duration of illness being in excess of six years, would indicate that, to date, the team has not fallen victim to the drift away from its target population.

Our survey, contrary to other professionals' views illustrates that our service users are able to make sensible and informed judgements about the health care they have received and about services they would find beneficial. This survey has also illustrated that the needs of the severely mentally ill are wide, varied and extend well beyond symptom management. The clinical needs cover such problems as anxiety, depression, trauma, social skills and the general needs involve help with isolation, independence, knowledge of illness and advice relating to social services and benefits. Historically, symptoms have been managed and other problems largely left unaddressed. Clearly, people with severe mental illness are not immune to other mental health problems. Epidemiological studies have recognised the prevalence of dual diagnosis (Reiger et al, 1990; Osher \& Drake, 1996). The many clients with dual diagnosis present significant challenges. The range of needs an individual has, if not assessed and planned for, can interfere with any treatment for their severe mental illness core symptoms (Drake \& Wallach, 1989; Osher et al, 1994). For example, the person with schizophrenia may also have an anxiety disorder. If not treated, either mental health problem may interfere with the treatment of the other.

A study like this, while interesting, is only truly worthwhile if it leads to changes which result in quality improvement. Such information can help move a CMHT to the point where it becomes a learning organisation (Garratt. 1987). Centres can focus their resources where they are most 


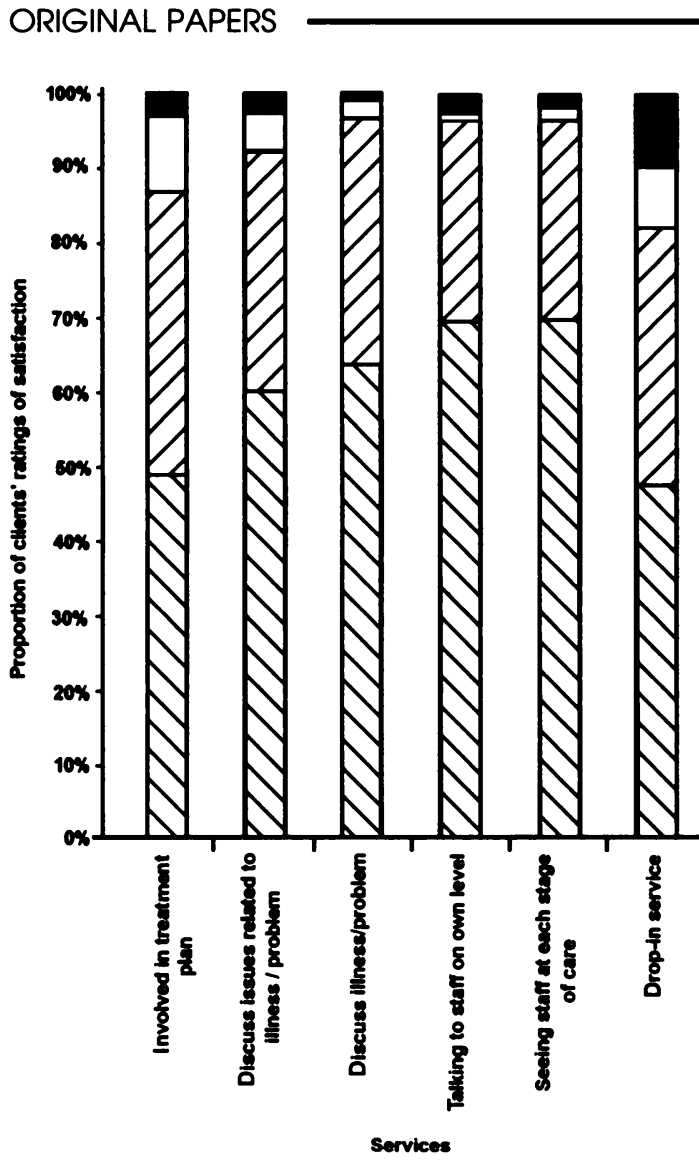

Fig. 2. Clients' satisfaction with services. $\mathbb{N}$, very satisfied; $\mathbf{n}$, fairly satisfied; $\square$, neutral; $\square$, fairly dissatisfied; $\square$, very dissatisfied.

needed. Instead of speculating about what services should offer, needs-led data can help direct service provision.

This survey has provided the CMHT with a baseline or benchmark to measure its performance against. Other teams can also use this data to compare their own clients' needs and satisfaction ratings.

Other lessons learned from this survey have led to the development of different service user involvement mechanisms. Each CMHT has a users' forum which meets regularly to provide input to services locally. Centres have sugges- tions boxes that users are encouraged to use. Advocacy groups have been developed in all areas. Coupled with such developments others are being piloted. One of the authors (G.R.) has developed a users' pool in one of the centres. This is a database of individual users who have agreed that we can approach them or they can approach us for suggestions and comments on any aspect of our service.

In summary, this study has illustrated the value of generating client feedback on their needs and satisfaction. Such a study is one of the first steps any organisation needs to embark upon in striving for quality improvements.

\section{References}

Department of Health (1989) Working for Patients. London: HMSO.

DEPARTMENT OF HEALTH AND SOCIAL SECURTY (1983) The Griffiths Management Enquiry Report. London: HMSO.

DRAKE, R. E. \& WALlach, M. A. (1989) Substance abuse among the chronically mentally ill. Hospital and Community Psychiatry. 40, 1041-1046.

FTIZPATRICK, R. (1991) Surveys of patient satisfaction. IImportant general considerations. British Medical Journal, 302, 887-889.

GARRATT. B. (1987) The Learning Organisation. London: Fontana.

NORUSIS, M. J. (1993) SPSS Release 6.0. Chicago, IL: SPSS Inc.

Osher, F. C., Drake, R. E., NoORdSky, D. L., et al (1994) Correlates and outcomes of alcohol use disorder among rural outpatients with schizophrenia. Journal of Clinical Psychiatry. 65. 109-113.

- \& - (1996) Reversing a history of unmet needs. American Journal of Orthopsychiatry, 66, 4-11.

REIGER, D. A., FARMER, M. B., RAE. D. S., et al (1990) Comorbidity of mental disorders with alcohol and other drug abuse. Journal of the American Medical Association, 264, 2511-2518.

Stallard. P., Hudson. J. \& Davis, B. (1992) Consumer evaluation in practice. Journal of Community and Applied Social Psychology, 2. 291-295.

George Ralston, Consultant Clinical Psychologist, Department of Clinical Psychology. Stobhill Hospital, Glasgow; *Sarah Beesley, Lecturer in Psychological Medicine/Honorary Senior Registrar. Department of Psychological Medicine, Gartnavel Royal Hospital, 1055 Great Western Road, Glasgow G12 OXH and John Bogue, Trainee Clinical Psychologist, Department of Clinical Psychology, Gartnavel Royal Hospital, Glasgow

*Correspondence 